\title{
EDITORIAL: \\ Journal News, Issue Preview, and Acknowledgments
}

\author{
William H. Barton
}

Welcome to the Fall 2009 (Volume 10, No. 2) issue of Advances in Social Work. If you are reading this during the holiday season, I hope this finds you well and enjoying a brief respite from your busy professional lives. Before previewing the contents of this issue, I'd like to bring a few things to your attention.

First, Advances will be publishing a special issue on "Social Work and Service Learning in the Age of Competency-based Education.” The issue will be co-edited by Virginia Majewski and Lisa McGuire. Participants at the conference "Assessing Professional Competencies through Service Learning," to be held in Indianapolis from June 16 to 18, 2010, are invited to submit papers for inclusion in this peer-reviewed issue, although others not attending the conference are also encouraged to submit papers as well. Papers may be either theoretical or research-focused. The submission deadline is September 1, 2010, with anticipated publication as the Spring 2011 issue. To view the complete call for papers, see the announcement on the journal's home page.

Second, Advances is getting increased exposure, both nationally and globally. We have had requests for permission to publish the Special Issue on "The Futures of Social Work” (Vol. 6, No. 1) as a book in Poland. We are now indexed in China via SOCOLAR. We are also seeing an increase in submissions from authors and registrations as reviewers from scholars outside of the United States. We welcome this development, and encourage more attention to international issues relevant for social work around the globe. We may well develop a Special Issue with an international focus at some point in the near future. Feel free to let us know of your interest in this arena.

Third, the editorial board has approved the adoption of a more formal review format, adapted with permission from one developed by another online journal, The Journal of the Scholarship of Teaching and Learning (http://www.iupui.edu/\%7Ejosotl/). Reviewers will now be directed to download a rubric and an evaluation form to be completed and uploaded. We hope this will enhance the review process further.

Now, on to the contents of this issue. We begin with "A Social Work Model of Empathy,” in which Karen E. Gerdes and Elizabeth A. Segal drawing from both social science and neuroscience sources, arrive at a model of empathy that seems particularly suited for social work. It is a model that invites further development and testing. Next comes "The Effect of Statutory Regulations on Social Workers' Decisions to Report Child Maltreatment,” a report of a study by Vicki Ashton on social workers’ perceptions of state law regarding the reporting of child maltreatment and the relationship of those perceptions with the likelihood that workers would report such incidents. The results indicate that workers do not share a common understanding of the law, and that their perceptions of the law are related to their likelihood of reporting maltreatment. The third article represents an international perspective, as Christopher Chitereka discusses "Social

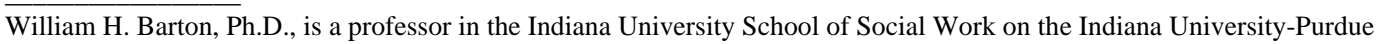
University Indianapolis campus.

Copyright (C) 2009 Advances in Social Work Vol. 10 No. 2 (Fall 2009), i-iii 
Work Practice in a Developing Continent: The Case of Africa.” Chitereka traces the colonial origins of social work in Africa, and highlights the tension between the remedial and social development approaches of the profession.

The remaining four articles focus on educational settings. First, in "Modern Social Support Structures: Online Social Networks and their Implications for Social Workers," Kala Chakradhar, Victor Raj and Arabella Raj present the results of a study on college students' use of Online Social Networks (OSN), such as Facebook. Their study examined the profiles of OSN users, the reasons for their use, and their experiences with OSNs. Continuing the discussion of technology and education is the next article, "Virtual Worlds and Social Work Education: Potentials for 'Second Life'." Here Robert Vernon, Lisa Lewis and Darlene Lynch report upon their use of "Second Life," a virtual world, in classroom and online education. They present the ways in which Second Life can be used to address selected competencies specified by the Council on Social Work Education's Educational Policy and Accreditation Standards, and conclude with a discussion of the potential and challenges posed by excursions into virtual worlds. Mark Thomas Lynch, Lening Zhang and Wynne S. Corr examine the relationship between social work research education and subsequent research activity in their article, "Research Training, Institutional Support, and Self-Efficacy: Their Impact on Research Activity of Social Workers.” Reporting on data collected from a random sample of social workers, they test a model in which Research Training and Institutional Support for Research within agencies each affect the Research Activity of practitioners directly and indirectly through their effects on the practitioners' research self-efficacy. Their results provide partial support for their model. In the concluding article, "Toward Building a Culture of Strengths in U.S. MSW Programs,” Linda Plitt Donaldson, Barbara P. Early and MinLing Wang present the results of an exploratory study in which they surveyed MSW programs regarding how and to what extent the strengths-based paradigm is integrated into their practice curricula. Their findings suggest that most programs are aware of and include strengths-based content, but that few seem to be moving beyond curriculum content to a more comprehensive culture of strengths.

I would like to take this opportunity to acknowledge the valuable contributions made by the many scholars who have completed one or more peer reviews of manuscripts since I began my term as editor with the Fall 2008 issue. The following have provided detailed, constructive reviews in a timely manner, and authors have frequently expressed their appreciation for the reviewers' guidance (apologies if our system has omitted anyone who has reviewed for us lately):

$\begin{array}{lll}\text { Margaret Adamek } & \text { Scott Anstadt } & \text { Carolyn Black } \\ \text { Javier Boyas } & \text { Daniel Brisson } & \text { Kala Chakradhar } \\ \text { Valerie Chang } & \text { Hyunkag Cho } & \text { Patricia Coccoma } \\ \text { Barry Cournoyer } & \text { James Daley } & \text { Rafael Engel } \\ \text { Robin Ersing } & \text { Gail Folaron } & \text { Rose Handon } \\ \text { Karen Harper-Dorton } & \text { David Hodge } & \text { Carol Hostetter } \\ \text { Grafton Hull } & \text { Jayshree Jani } & \text { Michael Kane }\end{array}$




$\begin{array}{lll}\text { Hea-Won Kim } & \text { Athena Kolbe } & \text { Kathy Lay } \\ \text { Dianne Loeffler } & \text { Virginia Majewski } & \text { Eldon Marshall } \\ \text { Stephen Marson } & \text { Jennifer Martin } & \text { Lisa McGuire } \\ \text { Shari Miller } & \text { Paul Newcomb } & \text { Philip Ouellette } \\ \text { Brian Perron } & \text { Phu Tai Phan } & \text { Cathy Pike } \\ \text { Gerald Powers } & \text { Marilynne Ramsey } & \text { Larry Reynolds } \\ \text { Diana Rowan } & \text { Michael Sherr } & \text { Patrick Sullivan } \\ \text { Robert Vernon } & \text { David Westhuis } & \text { Scott Wilks } \\ \text { Sabrina Williamson } & \text { Joanne Yaffe } & \end{array}$

If you happen to be reading this and have not yet registered with the journal, it's free and easy to do. Benefits include email notification whenever a new issue is published, the opportunity to serve as a peer reviewer for manuscripts received by the journal, and easy access to manuscript submission. If you do register, please consider also enrolling as a reviewer. To do so, when you are filling out the requested profile information, just check the box next to "Reviewer" near the bottom of the page and then indicate the topics you are interested in reviewing in the textbox provided. It is my intent not to overburden individual reviewers, and the more reviewers we have, the easier that is to do.

Finally, please consider submitting your work to Advances in Social Work. We do offer an exceptionally quick turnaround - authors can usually expect to receive the peer reviews and initial editorial decision within two to three months of submission. The online format means that we are not constrained by an issue's page length, and so backlogs of accepted manuscripts rarely occur. To submit a manuscript, you must first register with the journal and select "Author" as one of your roles in your profile. Then, when you wish to submit a manuscript, log in, select "Author" and follow the detailed instructions.

Thanks are due to the Editorial Board for their conscientious oversight of the journal, to the Indiana University School of Social Work and its Dean, Michael Patchner, for supporting the work of the Editor, to the University Library at IUPUI for providing the open access online platform, to Kristi Palmer for invaluable technical assistance with the journal's website, and to Julia Carter for administrative support.

May the year 2010 bestow opportunities and support upon our profession, the world, and each of its inhabitants.

William H. Barton, Ph. D., Professor

Editor, Advances in Social Work

Indiana University School of Social Work

902 West New York Street

Indianapolis, IN 46201

(317) 274-6711

wbarton@iupui.edu 